\title{
Application of molecularly imprinted polymer designed for the selective extraction of ketoprofen from wastewater
}

\author{
Lawrence Mzukisi Madikizela1*, Silindile Senamile Zunngu' ${ }^{1}$, Nomchenge Yamkelani Mlunguza', \\ Nikita Tawanda Tavengwa ${ }^{2}$, Phumlane Selby Mdluli' and Luke Chimuka ${ }^{3}$ \\ 'Department of Chemistry, Durban University of Technology, PO Box 1334, Durban, 4000, South Africa \\ ${ }^{2}$ Department of Chemistry, School of Mathematical and Natural Sciences, University of Venda, Private Bag X5050, Thohoyandou, 0950, South Africa \\ ${ }^{3}$ Molecular Sciences Institute, University of Witwatersrand, Private Bag X3, Johannesburg, 2050, South Africa
}

\begin{abstract}
A molecularly imprinted polymer (MIP) that is selective to ketoprofen was synthesized and applied in the adsorption of the target compound from water. The MIP was synthesized using a bulk polymerization method at high temperatures $\left(60-80^{\circ} \mathrm{C}\right)$, where ketoprofen, 2 -vinylpyridine, ethylene glycol dimethacrylate, toluene and 1,1'-azobis(cyclohexanecarbonitrile) were used as template, functional monomer, cross-linker, porogen and initiator, respectively. Non-imprinted polymer (NIP) was synthesized similarly to the MIP but in the absence of ketoprofen. From molecular dynamics simulation, the nature of interactions that occurred between the template and the functional monomer were found to be based on hydrogen bonding. This was confirmed experimentally, where a high extraction efficiency of $\geq 90 \%$ was obtained at acidic conditions (pH 5) due to the protonation of ketoprofen. A contact time of $45 \mathrm{~min}$ was sufficient for the maximum adsorption of ketoprofen from $10 \mathrm{~mL}$ spiked water using $8 \mathrm{mg}$ of the adsorbent. MIP showed greater selectivity than NIP by achieving a relative selectivity coefficient of 7.7 towards ketoprofen in the presence of structurally related pharmaceuticals. Furthermore, the order of sorption onto the MIPs from water was ketoprofen $>$ fenoprofen $>$ gemfibrozil. From a modelling perspective, the Langmuir adsorption isotherm and pseudo-second-order kinetic model gave the best fit, with maximum adsorption capacity of $8.24 \mathrm{mg} \cdot \mathrm{g}^{-1}$ and sorption rate constant of $0.25 \mathrm{mg} \cdot \mathrm{g}^{-1} \cdot \mathrm{min}^{-1}$ for MIP. This was translated to chemisorption of ketoprofen onto the homogeneous MIP binding sites. This work demonstrated the great potential of MIP in selective recognition of ketoprofen from wastewater relative to closely related compounds.
\end{abstract}

Keywords: ketoprofen, molecularly imprinted polymer, water, adsorption, molecular dynamics simulation, hydrogen bonding

\section{INTRODUCTION}

The presence of pharmaceutical compounds in surface water and wastewater has been known since the 1960s (Stumm-Zollinger and Fair, 1965). Pharmaceuticals are known as biologically active compounds that have a particular mode of action in humans and animals (Tiwari et al., 2017). Since the 1960s, the occurrence and fate of pharmaceuticals in the environment have attracted the devotion of the scientific community to assess the effectiveness of environmental policies (Kermia et al., 2016; Patrolecco et al., 2016; Pena et al., 2008; Zorita et al., 2008). In recent times, pharmaceuticals have been recognized as a class of environmental pollutants and they are becoming increasingly problematic contaminants of either surface water or groundwater around industrial and residential communities.

The sources of pharmaceuticals in surface water include wastewater treatment plants (WWTPs), households, effluent from pharmaceutical industries, and health service centres (Bayen et al., 2013; Félix-Cañedo et al., Kyzas et al., 2015; Santos et al., 2005). Pharmaceuticals such as ketoprofen are easily transported from wastewater to other water matrices. This is due to water being a good carrying medium for polar and semi-polar compounds (Pavlović et al., 2007). Globally, ketoprofen is a well-known pollutant in water matrices (Hanamoto et al., 2016; Martinez-Sena et al., 2016; Spongberg

To whom all correspondence should be addressed.

证 +27313732315

e-mail: lawrencem2@dut.ac.za

Received 5 September 2017; accepted in revised form 11 June 2018 et al., 2011). However, there are very few recent studies on the occurrence of ketoprofen in South African aqueous environments (Agunbiade and Moodley, 2016; Madikizela et al., 2014; Zunngu et al., 2017). In surface water and wastewater, ketoprofen is usually detected with other non-steroidal antiinflammatory drugs (NSAIDs) (Laven et al., 2009; Togola et al., 2007; Yu et al., 2013).

Due to the complexity of environmental samples, selective analytical methods are required for the analysis of compounds such as ketoprofen. Nowadays, molecularly imprinted polymers (MIPs) are being designed to improve the selectivity of analytical methods. Molecular imprinting technology is used for the preparation of highly specific binding sites for small molecules (Madikizela et al., 2016). The imprinting process involves the generation of cavities containing functional sites which are complementary to the target analyte with respect to shape, size and functional groups, within a highly cross-linked polymer matrix (Farrington and Regan, 2007; Gholivand et al., 2012). Most commonly, during molecular recognition the target compounds interact with MIP through non-covalent bonding, ionic interaction and hydrophobic interaction methods (Feng et al., 2009). For a MIP to possess such interactions, polymerization is usually carried out following bulk polymerization, in situ polymerization, suspension polymerization, and multi-step-swelling polymerization approaches (Dai et al., 2012; Ferrari et al., 2003; Murray and Örmeci, 2012).

Since an optimal target molecule and functional monomer interaction has a determining impact on successful imprinting, the choice of appropriate monomers plays 
a critical role in a successful imprinting process (Kubo and Otsuka, 2016). The best functional monomers are normally selected based on a trial-and-error method, which is expensive and time-consuming (Augusto et al., 2010; Rostamizadeh et al., 2012; Sobiech et al., 2014). Nowadays, with the advent of computational chemistry, the computeraided study of MIPs has been investigated as a rational and fast technique to search for optimal imprinting conditions (Rostamizadeh et al., 2012). Also, the use of molecular dynamics simulations and computational screening to identify functional monomers capable of strong interaction with the target molecule has been investigated (Dong et al., 2009; Rostamizadeh et al., 2012).

Although, the molecular imprinting technique has been widely used for polymer synthesis, few studies have applied computational modeling in order to investigate interactions that occur between target molecule and functional monomer. Molecular dynamics simulations are a powerful tool to investigate complex systems made of thousands of atoms, at reasonable computational costs (Monti et al., 2006; O’Mahony et al., 2007; Riahi et al., 2009). The properties of molecules are affected by the surrounding environment and accurate molecular dynamic simulations must include a proper description of the existing interactions. Simulations are based on classical mechanical force fields that describe non-covalent interactions, H-bonding, van-der-Waals forces, $\pi-\pi$ interactions and electrostatic interactions (Dong et al., 2009). Molecular dynamics simulation, in canonical ensemble at constant atom number, volume and temperature (NVT), has been utilized to fully understand the interactions of pharmaceuticals with 2-vinylpyridine (Madikizela et al., 2016; Riahi et al., 2009).

With ketoprofen being a well-known water contaminant, it is vital to synthesize a MIP for it and vigorously study how it interacts with this sorbent. MIPs play a crucial role in sample preparation through the selective extraction of target compounds from various matrices; therefore, it is important to understand the sorption mechanisms in order to carefully design them. There is detailed information on the application of molecular dynamics simulation to study the interactions between the templates and functional monomers used in molecular imprinting; however, the complex for ketoprofen and 2-vinylpyridine has never been studied. Therefore, this is the first detailed study to use molecular dynamics simulations for the evaluation of ketoprofen recognition by MIPs. The aims of the present study were to study the factors that affect the adsorption of ketoprofen onto MIP synthesized using bulk polymerization process and to investigate the adsorption mechanism.

\section{EXPERIMENTAL}

\section{Chemicals}

Ketoprofen ( $\geq 98 \%$ ), 2-vinylpyridine (97\%), HPLC-grade methanol ( $\geq 99.9 \%), 1,1^{\prime}$-azobis-(cyclohexanecarbonitrile) (98\%), ethylene glycol dimethacrylate (98\%), HPLC-grade chloroform ( $\geq 99.8 \%$ ) and toluene $(99.7 \%)$ were purchased from Sigma-Aldrich (Steinheim, Germany). HPLC-grade acetonitrile $(\geq 99.9 \%)$ and glacial acetic acid (100\%) were purchased from Merck (Darmstadt, Germany). Formic acid (approx. 98\%) and fenoprofen $(\geq 97 \%)$ were purchased from Fluka (Steinheim, Germany). Gemfibrozil was purchased from J \& H Chemicals Co. Ltd (Hangzhou, China).

\section{Molecular dynamics simulation}

Molecular dynamics simulations were executed in order to understand the nature of molecular interactions that occur between 2-vinylpyridine as functional monomer and ketoprofen as the template. These were performed in canonical ensemble at constant NVT. Discover Module of Materials Studio (version 7.0) was used to perform the simulations. In this work, COMPASS force field was used to calculate the intermolecular interaction energy and bond length between ketoprofen and 2-vinylpyridine. This was done after the optimum conformation of the ketoprofen-2-vinylpyridine configuration was established; thereafter, ketoprofen was removed from the system which allowed for a single-point energy calculation for 2-vinylpyridine. Then, a single-point energy calculation was performed on ketoprofen only. Prior to the execution of molecular dynamics simulations, all structural configurations were subjected to energy minimization for geometry optimization using minimizer incorporated in the discover module of Materials Studio. For minima calculation, a maximum iteration of 100000 was used with an ultrafine convergence level. This resulted in molecular dynamic simulation using NVT lasting for 100 ps with a time step of $1 \mathrm{fs}$. Similar conditions were applied to investigate the interactions that occur between 2-vinylyridine and its competitors (fenoprofen and gemfibrozil).

\section{Synthesis of molecularly imprinted polymer}

The synthesis of MIP for ketoprofen has been published in our previous work (Zunngu et al., 2017). The synthesis was carried out by mixing $25 \mathrm{mg}$ of ketoprofen with $54 \mu \mathrm{L}$ of 2 -vinylpyridine. The mixture was stirred at room temperature in a $50 \mathrm{~mL}$ round-bottomed flask containing $10 \mathrm{~mL}$ of acetonitrile/toluene $(1: 9, \mathrm{v} / \mathrm{v})$ porogenic mixture for $30 \mathrm{~min}$. Thereafter, the reaction vessel was placed on ice to prevent premature polymerization. Ethylene glycol dimethacrylate (4.77 mL) and $100 \mathrm{mg}$ of 1,1'-azobis-(cyclohexanecarbonitrile) were added. The mixture was purged with nitrogen gas for $10 \mathrm{~min}$, sealed and stirred in an oil bath at $60^{\circ} \mathrm{C}$ for $16 \mathrm{~h}$ to initiate polymerization. After $16 \mathrm{~h}$, the temperature was increased to $80^{\circ} \mathrm{C}$ and maintained for $24 \mathrm{~h}$ to achieve a solid monolith polymer. The polymer was dried to constant mass at $80^{\circ} \mathrm{C}$ followed by grinding and sieving to collect particles that ranged from 25 to $90 \mu \mathrm{m}$ in diameter. The control, non-imprinted polymer (NIP) was synthesized and treated likewise, with the omission of ketoprofen in the reaction mixture. Thereafter, both MIP and NIP particles were washed repeatedly with a mixture of acetic acid: acetonitrile (1:9, v/v) until ketoprofen could not be detected by the former in the high performance liquid chromatography (HPLC) system.

\section{Instrumentation}

A Shimadzu HPLC (Kyoto, Japan) system that consisted of an online mobile phase degasser unit (Model: DGU-20A5), $20 \mu \mathrm{L}$ sample loop, pump (Model: LC-20AT), and UV/visible detector (Model: SPD-20A) was used for the determination of the pharmaceuticals. The mobile phase conditions consisted of a mixture of acetonitrile and $0.2 \%$ formic acid in water $(60: 40, \mathrm{v} / \mathrm{v})$ at a flow rate of $1 \mathrm{~mL} \cdot \mathrm{min}^{-1}$. Separation of the analytes was performed on a Gemini $\mathrm{C}_{18}$ HPLC column with dimensions of $150 \mathrm{~mm} \times 4.6 \mathrm{~mm} \times 5 \mu \mathrm{m}$ obtained from Phenomenex (California, USA). Shimadzu LC solutions 
software was used for data collection and processing. Detector wavelength was set at $255 \mathrm{~nm}$.

Spectroscopic characterizations were done by nuclear magnetic resonance (NMR) and Fourier-transform infrared (FTIR) techniques. Agilent VNMRS Wide Bore $500 \mathrm{MHz}$ NMR spectrometer with a ${ }^{1} \mathrm{H}$ frequency of $500 \mathrm{MHz}$ and ${ }^{a}{ }^{13} \mathrm{C}$ frequency of $125 \mathrm{MHz}$ was used. The spectra were acquired utilizing a dual-channel $4 \mathrm{~mm}$ Chemagnetics TM T3 HX MAS probe using $4 \mathrm{~mm}$ zirconia rotors. The crosspolarization (CP) spectra were recorded at $25^{\circ} \mathrm{C}$ with proton decoupling using a recycle delay of $10 \mathrm{~s}$. The $\mathrm{CP}$ pulse power parameters were optimized for the Hartmann-Hahn match using a glycine standard sample. The radio frequency fields for the match were $\gamma \mathrm{CB} 1 \mathrm{C}=\gamma \mathrm{HB} 1 \mathrm{H} \approx 55 \mathrm{kHz}$. The contact time for cross-polarization was optimized to $2.0 \mathrm{~ms}$. Magicangle-spinning (MAS) was performed at 10000 revolutions per second $(10 \mathrm{kHz})$. FTIR used was equipped with attenuated total reflection (Perkin Elmer, Llantrisant, United Kingdom) with solid samples analysed without any treatment.

A scanning electron microscopy (SEM), JOEL model JSM $6700 \mathrm{~F}$ (Tokyo, Japan) was used to study the polymer morphology.

Surface area, total pore volume and average pore diameter for both MIP and NIP were evaluated using the Flow Prep 060 instrument from Micromeritics (Aachen, Germany).

The zeta potentials for MIP dispersed in water adjusted to $\mathrm{pH} 5$ and 9 were determined at $25^{\circ} \mathrm{C}$ using a zeta instrument (Model: Nanosight NS 500) obtained from Malvern Instruments Limited (Worcestershire, UK).

\section{Optimization of adsorption parameters}

Parameters that could influence the adsorption of ketoprofen onto MIP were optimized. In our previous work (Zunngu et al., 2017), it was clearly demonstrated through the application of molecularly imprinted solid-phase extraction (MISPE) that the performance of the NIP for adsorption of ketoprofen yields poor results when compared to MIP. Therefore, the focus of the present study was based more on adsorption of ketoprofen onto MIP. Initially, $10 \mathrm{~mL}$ of ketoprofen standard $\left(1 \mathrm{mg} \cdot \mathrm{L}^{-1}\right)$ was prepared in 3 organic solvents (acetonitrile, toluene and chloroform), and the adsorption process into $8 \mathrm{mg}$ of MIP was allowed to occur overnight. This was important as the nature of the solvent used to dissolve the target compound is known to influence the batch adsorption capacity for the MIP (Kizhakekuthiathottil and Beena, 2011; Navarro-Villoslada et al., 2004). The ketoprofen standard prepared in water was treated likewise. Extraction efficiency was determined in each case.

Thereafter, adsorption parameters in the batch mode, such as sample $\mathrm{pH}(3-9)$, polymer mass $(8-25 \mathrm{mg})$, contact time (5-60 $\mathrm{min}$ ) and initial concentration of target molecule (0.001-70 mg. $\left.\mathrm{L}^{-1}\right)$, were optimized for the uptake of ketoprofen by MIP sorbent from water solutions. This was done by holding all the other parameters constant while varying one. For example, when monitoring the effect of polymer amount, the sorbent mass was changed from 8 to $25 \mathrm{mg}$, while contact time, adsorption medium and its volume, sample $\mathrm{pH}$, and concentration of ketoprofen in spiked solutions were kept constant. Each experiment was repeated 3 times. In each case, the extraction efficiency or the adsorption capacity was calculated using Eqs 1 and 2, respectively.

$$
\text { Extraction efficiency }(\%)=\frac{\left(C_{0}-C_{\mathrm{e}}\right)}{C_{\mathrm{o}}} \times 100
$$

$$
\text { Adsorption capacity }\left(\mathrm{mg} \cdot \mathrm{L}^{-1}\right)=\frac{\left(C_{o}-C_{\mathrm{e}}\right) V}{W}
$$

where $C_{\mathrm{o}}$ and $C_{\mathrm{e}}$ are the initial concentration $\left(\mathrm{mg} \cdot \mathrm{L}^{-1}\right)$ before the adsorption and the final concentration $\left(\mathrm{mg} \cdot \mathrm{L}^{-1}\right)$ of target compound remaining in solution after adsorption, respectively. $V$ and $W$ represent the volume (L) of the solution and the mass (g) of the polymer, respectively.

\section{Selectivity studies}

The selectivity of the MIP for ketoprofen was tested in batch rebinding experiments using optimum conditions, which were $10 \mathrm{~mL}$ of deionized water spiked with $1 \mathrm{mg} \cdot \mathrm{L}^{-1}$ of each of the analytes (ketoprofen, fenoprofen and gemfibrozil). Thereafter, the concentration of the un-adsorbed compounds in solution were measured by HPLC. This was followed by the determination of the distribution coefficients $\left(K_{\mathrm{d}}\left(\mathrm{mL} \cdot \mathrm{g}^{-1}\right)\right)$ using Eq. 3. Thereafter, the selectivity coefficients for the adsorption of ketoprofen in the presence of the competing species was calculated using Eq. 4. Furthermore, the selectivity of the MIP in relation to the NIP was measured using the relative selectivity coefficient $\left(K^{\prime}\right)$ which was calculated using Eq. 5.

$$
\begin{gathered}
K_{\mathrm{d}}=\frac{\left(C_{0}-C_{\mathrm{e}}\right)}{W C_{\mathrm{e}}} V \\
K=\frac{K_{\mathrm{d}} \text { (ketoprofen) }}{K_{\mathrm{d}} \text { (competitor) }} \\
\mathrm{K}^{\prime}=\frac{K(\mathrm{MIP})}{K(\mathrm{NIP})}
\end{gathered}
$$

\section{RESULTS AND DISCUSSION}

\section{Synthesis of molecularly imprinted polymer}

\section{Computational analysis of a pre-polymerization mixture}

Synthesis of the MIP for ketoprofen was performed using standard reagents that are normally used when preparing polymers for acidic pharmaceuticals (Sun et al., 2008). Such reagents may be commonly used, but for the success of molecular imprinting it is always important to evaluate the possible interactions that will occur in the pre-polymerization complex. In this case, the nature of interactions that occur between the widely used 2 -vinylpyridine and ketoprofen were investigated. Prior to the execution of molecular dynamics simulations, the Mulliken charges for all the atoms present in ketoprofen (Fig. 1a) and 2-vinylpyridine (Fig. 1b) were assigned (Table 1). From the Mulliken charges, it was observed that hydrogen bonding could occur where the nitrogen atom $(6 \mathrm{~N})$ of 2-vinylpyridine will accept the proton $(33 \mathrm{H})$ from the carboxylic group of ketoprofen. Molecular dynamics simulation confirmed this observation (Fig. 1c). The resulting bond distance between the binding atoms of the two compounds was $1.837 \AA$ A. In previous studies, the hydrogen bond distances reported were in the range of 1.646 to 2.160 Å (Han et al., 2017; Madikizela et al., 2016; Puzio et al., 2013; Suriyanarayanan et al., 2017). Furthermore, the binding energy $(\Delta E)$ for the complex that results from the interactions 

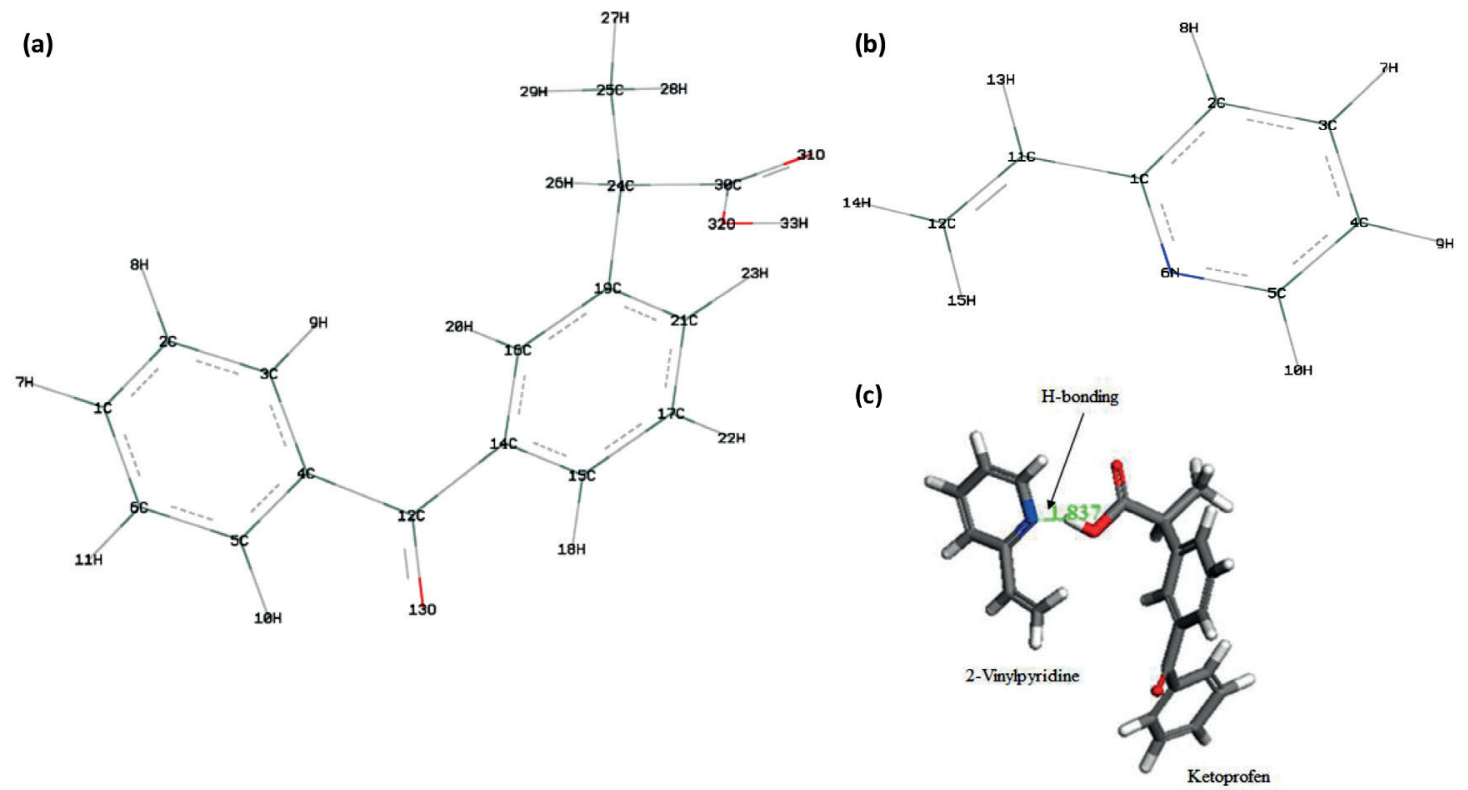

Figure 1

Molecular interactions between ketoprofen (a) and 2-vinylpyridine (b) to form the complex (c)

\begin{tabular}{|c|c|c|c|c|c|}
\hline \multicolumn{6}{|c|}{$\begin{array}{c}\text { TABLE 1 } \\
\text { Mulliken charges of ketoprofen and 2-vinylpyridine }\end{array}$} \\
\hline \multicolumn{3}{|c|}{ Ketoprofen } & \multicolumn{3}{|c|}{ 2-vinylpyridine } \\
\hline $\begin{array}{l}\text { Atom } \\
\text { number }\end{array}$ & Atom & $\begin{array}{l}\text { Atomic } \\
\text { charges }\end{array}$ & $\begin{array}{l}\text { Atom } \\
\text { number }\end{array}$ & Atom & $\begin{array}{l}\text { Atomic } \\
\text { charges }\end{array}$ \\
\hline 1 & $\mathrm{C}$ & -0.090 & 1 & $\mathrm{C}$ & 0.192 \\
\hline 2 & C & -0.068 & 2 & C & -0.103 \\
\hline 3 & C & -0.097 & 3 & $\mathrm{C}$ & -0.103 \\
\hline 4 & $\mathrm{C}$ & 0.026 & 4 & $\mathrm{C}$ & -0.104 \\
\hline 5 & C & -0.062 & 5 & C & 0.051 \\
\hline 6 & C & -0.103 & 6 & $\mathrm{~N}$ & -0.314 \\
\hline 7 & $\mathrm{H}$ & 0.112 & 7 & $\mathrm{H}$ & 0.100 \\
\hline 8 & $\mathrm{H}$ & 0.132 & 8 & $\mathrm{H}$ & 0.082 \\
\hline 9 & $\mathrm{H}$ & 0.129 & 9 & $\mathrm{H}$ & 0.089 \\
\hline 10 & $\mathrm{H}$ & 0.156 & 10 & $\mathrm{H}$ & 0.095 \\
\hline 11 & $\mathrm{H}$ & 0.114 & 11 & C & -0.105 \\
\hline 12 & C & 0.263 & 12 & C & -0.254 \\
\hline 13 & $\mathrm{O}$ & -0.473 & 13 & $\mathrm{H}$ & 0.097 \\
\hline 14 & C & 0.015 & 14 & $\mathrm{H}$ & 0.118 \\
\hline 15 & $\mathrm{C}$ & -0.065 & 15 & $\mathrm{H}$ & 0.161 \\
\hline 16 & $\mathrm{C}$ & -0.102 & & & \\
\hline 17 & $\mathrm{C}$ & -0.113 & & & \\
\hline 18 & $\mathrm{H}$ & 0.158 & & & \\
\hline 19 & C & 0.031 & & & \\
\hline 20 & $\mathrm{H}$ & 0.144 & & & \\
\hline 21 & C & -0.091 & & & \\
\hline 22 & $\mathrm{H}$ & 0.115 & & & \\
\hline 23 & $\mathrm{H}$ & 0.102 & & & \\
\hline 24 & $\mathrm{C}$ & -0.099 & & & \\
\hline 25 & $\mathrm{C}$ & -0.386 & & & \\
\hline 26 & $\mathrm{H}$ & 0.127 & & & \\
\hline 27 & $\mathrm{H}$ & 0.165 & & & \\
\hline 28 & $\mathrm{H}$ & 0.184 & & & \\
\hline 29 & $\mathrm{H}$ & 0.111 & & & \\
\hline 30 & C & 0.515 & & & \\
\hline 31 & $\mathrm{O}$ & -0.459 & & & \\
\hline 32 & $\mathrm{O}$ & -0.714 & & & \\
\hline 33 & $\mathrm{H}$ & 0.323 & & & \\
\hline
\end{tabular}

between 2-vinylpyridine and ketoprofen was used to quantify the strength of the hydrogen bonding. Binding energy was calculated using Eq. 6, as explained in previous studies (Farrington, Regan, 2007; Madikizela et al., 2016):

$$
\Delta E=E_{\text {(complex) }}-E_{\text {(template) }}-E_{(2-\text { vinylpyridine) }}
$$

The obtained binding energy for the complex that is formed by ketoprofen and 2-vinylpyridine was $-11.97 \mathrm{Kcal} \cdot \mathrm{mol}^{-1}$, which corresponded well with the binding energies obtained in other similar complexes (Farrington et al., 2006; Gholivand et al., 2012; Madikizela et al., 2016; Zhang et al., 2008). Therefore, these results confirmed the existence of hydrogen bonding between ketoprofen and 2-vinylpyridine.

\section{Characterization of the synthesized polymers}

\section{Scanning electron microscopy}

Scanning electron microscopy (SEM) was used to study the polymer morphology. The results (Fig. 2) clearly show the differences between the morphology of the MIP (Fig. 2a) and NIP (Fig. 2b). It was observed that the surface of the MIP is rougher, resulting in the availability of more surface area for ketoprofen adsorption, and has large pore sizes compared to the NIP. The pores on the surface improved the mass transfer of ketoprofen from the solution to the pores of the sorbent. This suggested that polymer morphology influenced the extraction of the target molecule from water.

\section{Brunauer, Emmett and Teller analysis}

Brunauer, Emmett and Teller (BET) results given in Table 2 show a greater surface area $\left(209 \mathrm{~m}^{2} \cdot \mathrm{g}^{-1}\right)$ for the MIP than the NIP $\left(95 \mathrm{~m}^{2} \cdot \mathrm{g}^{-1}\right)$. Previous work has shown that a MIP with a higher surface area yields a higher adsorption capacity than its corresponding NIP with lower surface area (Dai et al., 2012; Song et al., 2015). It was also observed that the MIP had 


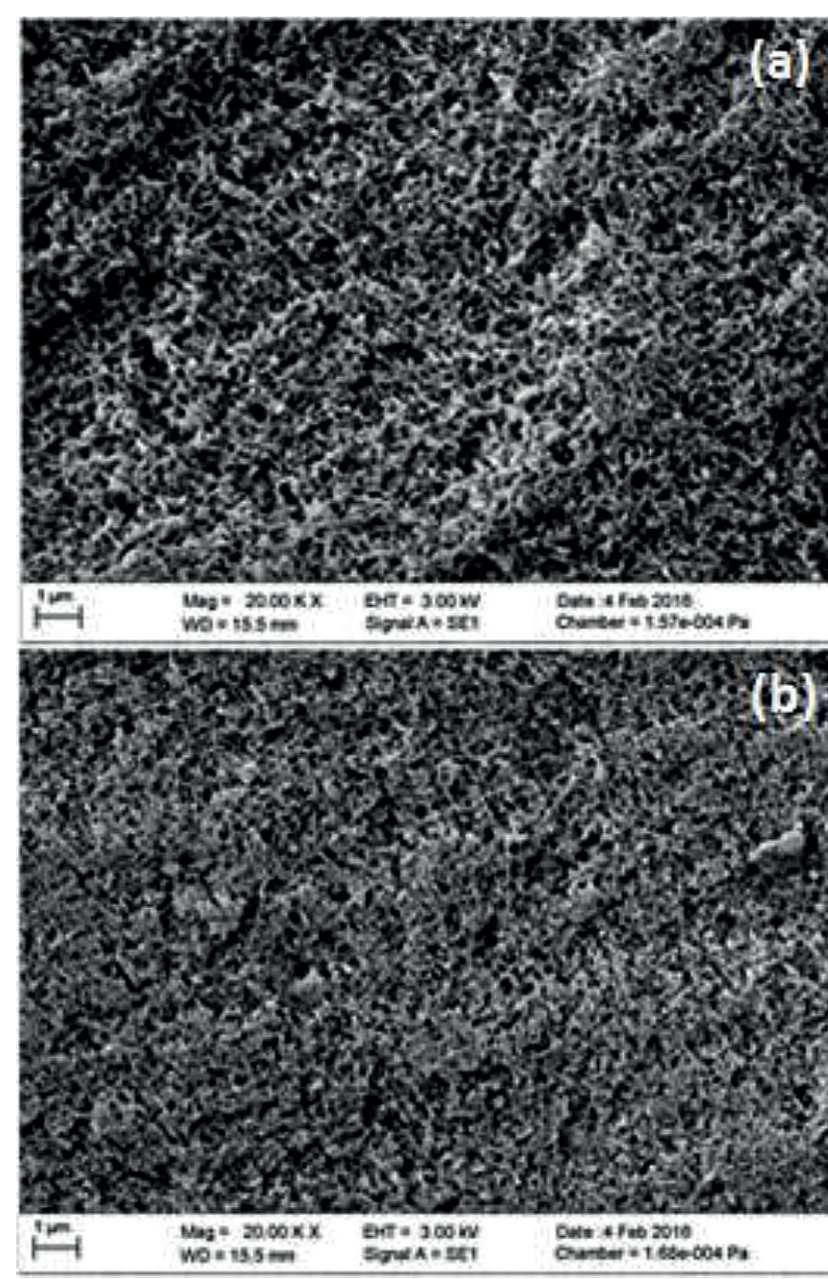

Figure 2

SEM micrographs of (a) MIP and (b) NIP

a higher total pore volume than the NIP. This corresponds well with SEM results, which were translated to MIP having larger pore sizes compared to the NIP. Furthermore, a bigger total pore volume for MIP implies that it has a higher sample load capacity than the NIP (Farrington and Regan, 2007). The average pore diameters for both MIP and NIP fall in the range of 2-50 nm, which indicates mesoporous structures in both polymers (Cormack and Elorza, 2004).

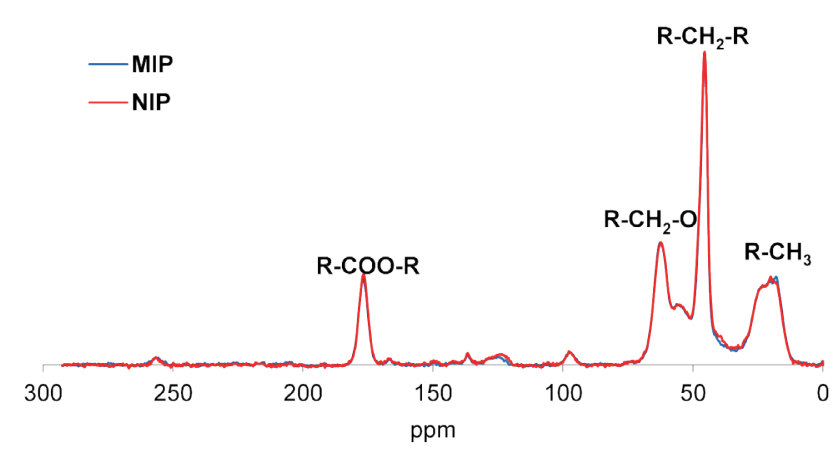

Figure 3

Solid-state 13C CP/MAS NMR spectra of the MIP and NIP

\begin{tabular}{|c|c|c|c|}
\hline \multicolumn{4}{|c|}{$\begin{array}{c}\text { TABLE } 2 \\
\text { Brunauer, Emmett and Teller analysis of polymers }\end{array}$} \\
\hline Polymer & $\begin{array}{l}\text { Surface area } \\
\qquad\left(\mathrm{m}^{2} \cdot \mathrm{g}^{-1}\right)\end{array}$ & $\begin{array}{c}\text { Total pore } \\
\text { volume }\left(\mathrm{cm}^{3} \cdot \mathrm{g}^{-1}\right)\end{array}$ & $\begin{array}{l}\text { Average pore } \\
\text { diameter }(\mathrm{nm})\end{array}$ \\
\hline MIP & 209 & 0.59 & 11.3 \\
\hline NIP & 95 & 0.30 & 12.6 \\
\hline
\end{tabular}

\section{Spectroscopic characterization of the synthesized} polymers

The solid-state ${ }^{13} \mathrm{C}$ CP/MAS NMR spectra for both MIP and NIP were identical (Fig. 3), implying the identical arrangement of carbon atoms in the polymeric network. The assigned major signals corresponded well with those given for MIPs and NIPs synthesized with similar reagents (Skogsberg et al., 2007; Madikizela and Chimuka, 2016 a). In addition, methyl (17 ppm), methylene (61 ppm) and $\mathrm{CO}_{2} \mathrm{R}(175 \mathrm{ppm})$ groups were all observed in the spectra, as expected due to the nature of imprinting, which uses a large amount of ethylene glycol dimethacrylate as a crosslinking monomer (Fig. 3). These strong resonances in the aliphatic region were associated with the cross-linking and functional monomers (2-vinylpyridine), whereas at the far end carbonyl grouping in $\mathrm{CO}_{2} \mathrm{R}$ is clearly visible, which is in good agreement with observations made elsewhere (Kizhakekuthiathottil and Beena, 2011; Skogsberg et al., 2007; Sobiech et al., 2016).

Similar structural arrangements for MIP and NIP were further confirmed with FTIR (Fig. 4). Strong intensities for $\mathrm{C}=\mathrm{O}$ and C-O groups at $\approx 1765$ and $\approx 1382 \mathrm{~cm}^{-1}$ indicated the high degree of cross-linking (EGDMA) agent in the polymer network (Pakade et al., 2011; Wang et al., 2009). The appearance of C-N stretch at $\approx 1323 \mathrm{~cm}^{-1}$ in all polymers' spectra was caused by the presence of cyanide groups in polymers that originate from the functional monomer and initiator. FTIR spectra of the polymers were identical in all peaks, which was an indication that they were similarly synthesized with the same pre-polymerization reagents, with only the omission of ketoprofen for NIP.

\section{Optimization of parameters for the adsorption of} ketoprofen by molecularly imprinted polymer

\section{Effect of adsorption medium}

This study is based on the adsorption of ketoprofen from water; however, the uptake of the compound from different solvent

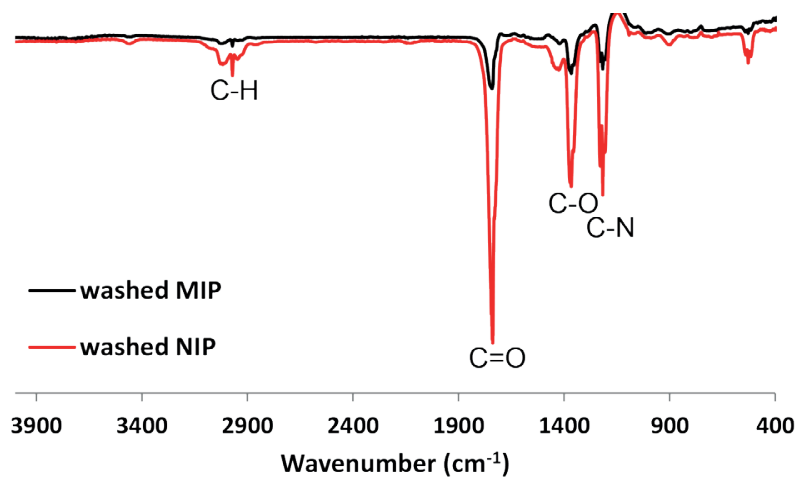

Figure 4

FTIR spectra of the synthesized MIP and NIP 
conditions was evaluated. The following organic solvents in the order of increasing polarity were investigated; toluene, chloroform and acetonitrile. In each case, other parameters were held constant while varying the extraction medium. The highest extraction efficiency (97\%) was achieved when ketoprofen was dissolved in water (Fig. 5). This was followed by good extraction efficiencies obtained when ketoprofen was extracted from chloroform (82\%) and toluene (62\%). Both chloroform and toluene are less polar than acetonitrile while ketoprofen has a polar group. This could easily promote the adsorption of polar ketoprofen onto MIP particles from chloroform and toluene while there are strong interactions between ketoprofen and acetonitrile. In addition, toluene was used in the porogenic mixture; therefore, similarly to our previous results, the adsorption occurs better in a solvent that was applied as porogen (Madikizela et al., 2016).

Furthermore, in the same previous study, Madikizela et al. (2016) observed low extraction efficiency in polar organic solvents due to the possible competition for hydrogen bonding in the MIP cavity that could occur between solvents and target compounds. Thereafter, subsequent experiments were conducted using water as the adsorption medium.

\section{Effect of sample pH}

The $\mathrm{pH}$ of the sample solution affects both the aqueous chemistry and the binding sites of the polymer, which in turn have an influence on the adsorption process (Madrakian et al., 2013). In the current study, $\mathrm{pH}$ was varied from 3 to 9 while other extraction conditions were kept constant. The results (Fig. 6) indicate that the extraction efficiency was higher at acidic $\mathrm{pH}$, which was significantly reduced as the $\mathrm{pH}$ was increased. This is in agreement with the findings reported in literature, where it has been demonstrated that at low water $\mathrm{pH}$ there is an increase in adsorption of acidic compounds to polymers with monomers containing nitrogen (Meischl et al., 2016). This could be explained by the protonation of acidic compounds in acidic media which results in adsorption through hydrogen bonding, as computationally demonstrated earlier. In order to avoid the excess usage of acids during $\mathrm{pH}$ adjustments, pH 5 was selected as optimum $\mathrm{pH}$ and used in the experiments that followed. This was further elaborated using the results from zeta potential (Fig. A1), where a MIP was dispersed in water under acidic and basic conditions. The average zeta potential of MIP at $\mathrm{pH} 5$ and 9 were $-30.3 \mathrm{mV}$ and $-15.6 \mathrm{mV}$, respectively. This means that the surface was more negatively charged at $\mathrm{pH} 5$ than $\mathrm{pH} 9$ which resulted in strong adsorption of protonated ketoprofen at acidic conditions.

\section{Effect of contact time}

The relationship between the amount of ketoprofen adsorbed and contact time with the MIP is shown in Fig. 7, where the other experimental conditions were fixed. In the studied time range (5-60 $\mathrm{min}$ ), the extraction efficiency varied from $75 \%$ to $80 \%$. In comparison, in our previous study we observed that the maximum adsorption of NSAIDs onto MIP could be achieved in as little as 2 min of contact time (Madikizela and Chimuka, 2016b). However, in order to ensure that there is sufficient contact between ketoprofen and MIP, 45 min was used in subsequent experiments.



Figure 5

Effect of solvents on the extraction efficiency of ketoprofen by MIP sorbent. Experimental conditions: sample $\mathrm{pH}$ (unadjusted neutral), contact time (45 min), polymer mass $(8 \mathrm{mg})$, sample volume $(10 \mathrm{~mL})$ and concentration of ketoprofen $\left(1 \mathrm{mg} \cdot \mathrm{L}^{-1}\right)(\mathrm{n}=3)$.

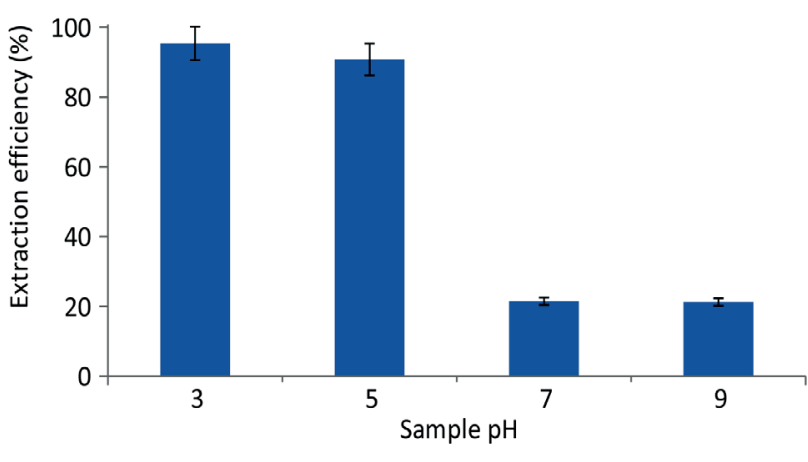

Figure 6

Effect of sample $\mathrm{pH}$ on the extraction efficiency of ketoprofen by MIP sorbent. Experimental conditions: $10 \mathrm{~mL}$ water, contact time ( $45 \mathrm{~min})$, polymer mass $(8 \mathrm{mg})$ and concentration of ketoprofen $\left(1 \mathrm{mg} \cdot \mathrm{L}^{-1}\right)(\mathrm{n}=3)$.

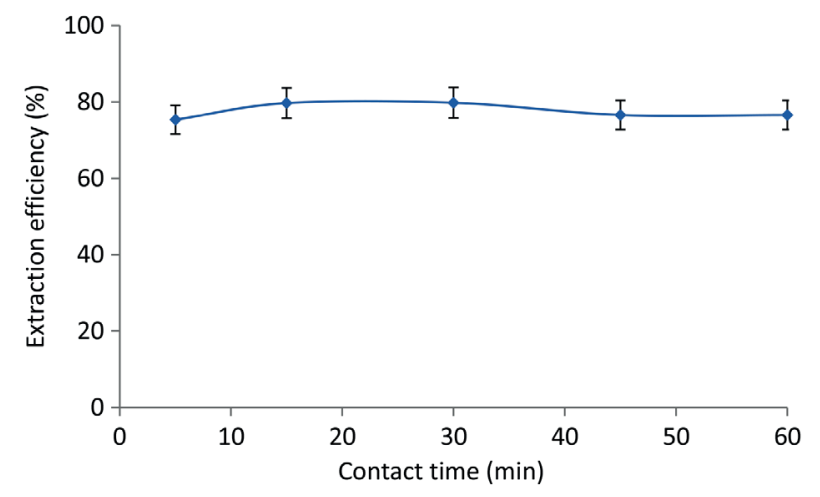

Figure 7

Effect of contact time on the extraction efficiency of ketoprofen by MIP sorbent. Experimental conditions: $10 \mathrm{~mL}$ water, sample $\mathrm{pH}$ 5, polymer mass of $8 \mathrm{mg}$ and concentration of ketoprofen at $1 \mathrm{mg} \cdot \mathrm{L}^{-1}(\mathrm{n}=3)$

\section{Effect of polymer mass}

The effect of polymer amount was investigated by varying the mass of the MIP from 8 to $20 \mathrm{mg}$ while the other experimental conditions were kept constant. In the studied adsorbent mass range, it was observed that the extraction efficiency was roughly independent of the polymer amount (Fig. 8), as the extraction efficiency varied slightly from 98 to $100 \%$. This 
means that any amount of MIP from $8 \mathrm{mg}$ and more could be able to extract $1 \mathrm{mg} \cdot \mathrm{L}^{-1}$ of ketoprofen efficiently. Furthermore, this implies that the equilibrium had already been established when the minimum mass of the MIP ( $8 \mathrm{mg}$ ) was used.

Normally, for lower masses, the extraction efficiency is expected to increase before attainment of equilibrium, where the increase in mass is directly proportional to the available adsorption sites (Tavengwa et al., 2013). In addition, the concentration of ketoprofen reported in South African wastewater is in the range of 0.38 to $6.40 \mu \mathrm{g} \cdot \mathrm{L}^{-1}$, which could indicate that any amount of MIP selected in this study is able to adsorb the acidic drug from environmental samples (Agunbiade and Moodley, 2016; Madikizela et al., 2014). Therefore, $8 \mathrm{mg}$ of MIP was used in subsequent experiments.

\section{Effect of initial concentration}

This experiment was carried out by varying the initial concentration of ketoprofen while keeping other parameters constant. The adsorption capacity increased linearly as a function of initial concentration; this was observed until 60 mg.L $\mathrm{L}^{-1}$ (Fig. 9). A small increase in adsorption capacity was observed in the concentration range of 60 to $70 \mathrm{mg} \cdot \mathrm{L}^{-1}$. This could indicate that the MIP was reaching saturation at higher concentrations. Due to the concentration of ketoprofen being expected at $\mu \mathrm{g} \cdot \mathrm{L}^{-1}$ levels in environmental samples, initial concentrations exceeding $70 \mathrm{mg} \cdot \mathrm{L}^{-1}$ were not investigated. In any case, this experiment was carried out in order to understand how the concentration of ketoprofen affects its adsorption onto the MIP. This is important as it enables the determination of the maximum adsorption capacity for the MIP.

\section{Selectivity of MIP}

The selectivity of the MIP was assessed using standard equations (Eqs 3-5) described earlier (Tavengwa et al., 2014; $\mathrm{Xu}$ et al., 2012). In the experimental set-up, deionized water was spiked with $1 \mathrm{mg} \cdot \mathrm{L}^{-1}$ of ketoprofen in the presence of equal amounts of fenoprofen and gemfibrozil used as competitors in a multi-component system. Fenoprofen and gemfibrozil are themselves acidic pharmaceuticals having similar physicochemical properties and size as ketoprofen (Table A1). Due to the presence of the carboxylic group in their chemical structures as well as ketoprofen, they are expected to form hydrogen bonds with 2-vinylpyrine used as functional monomer in molecular imprinting. Based on the molecular dynamics study, the hydrogen bonds between competitors and 2 -vinylpyridine occur similarly to that between ketoprofen and 2-vinylpyridine (Fig. A2).

The adsorption of pharmaceutical drugs into MIP was allowed to equilibrate using the optimized experimental conditions. The $K_{\mathrm{d}}$ values obtained for adsorption of ketoprofen, fenoprofen and gemfibrozil on MIP were 1065,16 and $175 \mathrm{~mL} \cdot \mathrm{g}^{-1}$, respectively (Table 3). This translated to the selectivity coefficient of 67 for the MIP. In comparison to the NIP, the relative selectivity coefficient

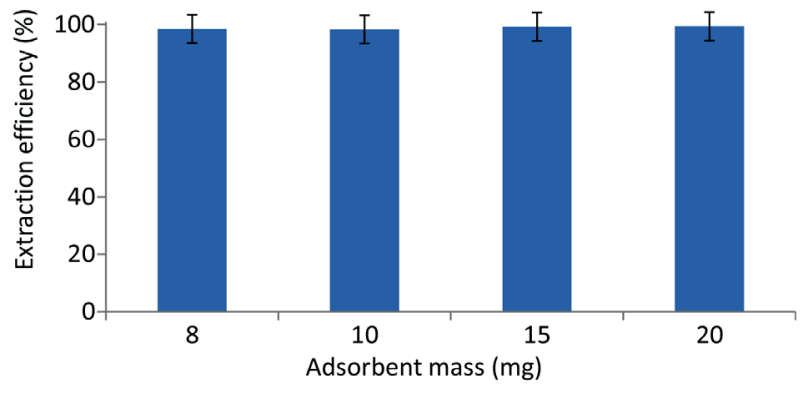

Figure 8

Effect of polymer amount on the extraction efficiency of ketoprofen by MIP sorbent. Experimental conditions: $10 \mathrm{~mL}$ water, sample $\mathrm{pH}$ 5, contact time of 45 min and concentration of ketoprofen at $1 \mathrm{mg} \cdot \mathrm{L}^{-1}(\mathrm{n}=3)$.

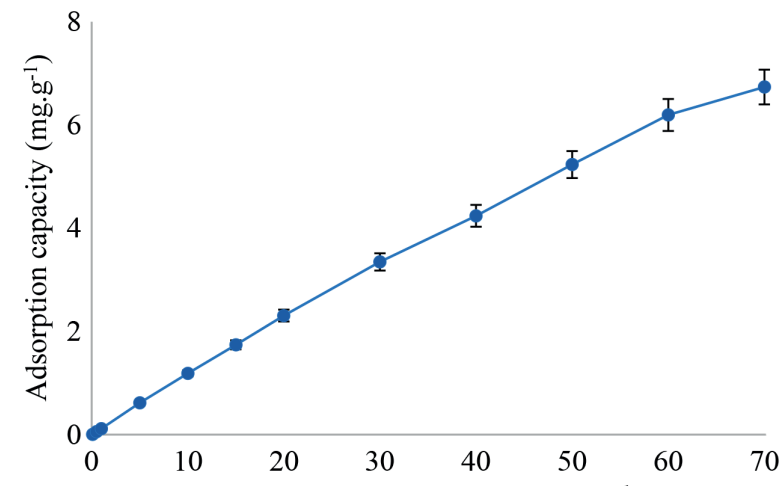

Figure 9

Effect of initial concentration of ketoprofen on the extraction efficiency of ketoprofen by MIP sorbent. Experimental conditions: $10 \mathrm{~mL}$ water, sample $\mathrm{pH}$, contact time of $45 \mathrm{~min}$, and polymer mass of $8 \mathrm{mg}(\mathrm{n}=3)$.

$\left(K^{\prime}\right)$ of 7.7 for the MIP was observed. This indicated that the selectivity is 8 and 2 times greater for ketoprofen in the presence of fenoprofen and gemfibrozil, respectively, compared to the NIP. These results indicated that the MIP was highly selective for ketoprofen recognition, relative to the NIP, in aqueous samples which resulted in a low selectivity coefficient (Mata et al., 2014). The order of sorption onto the MIP was ketoprofen $>$ fenoprofen $>$ gemfibrozil. Although ketoprofen and its competitors have similar size and functional groups, the MIP selectivity towards ketoprofen is influenced by molecular recognition due to differences in the shape of the target compound and its competitors.

\section{Molecularly imprinted polymer surface adsorption mechanism}

Pseudo-first-order (Eq. 7) and pseudo-second-order (Eq. 8) kinetic models were used to investigate the nature of adsorption for ketoprofen on MIP.

TABLE 3

Distribution coefficients, selectivity coefficients and relative selectivity coefficients for the MIP and NIP

\begin{tabular}{|c|c|c|c|c|c|c|c|c|}
\hline \multirow[t]{2}{*}{ Polymer } & \multicolumn{2}{|c|}{$K_{d}\left(\mathrm{~mL} \cdot \mathrm{g}^{-1}\right)$} & \multirow[t]{2}{*}{$K$} & \multirow[t]{2}{*}{$K^{\prime}$} & \multicolumn{2}{|c|}{$K_{\mathrm{d}}\left(\mathrm{mL} \cdot \mathrm{g}^{-1}\right)$} & \multirow[t]{2}{*}{$K$} & \multirow[t]{2}{*}{$K^{\prime}$} \\
\hline & Ketoprofen & Fenoprofen & & & Ketoprofen & Gemfibrozil & & \\
\hline MIP & 1065 & 15.9 & 67 & 7.7 & 1065 & 175 & 6.1 & 2.03 \\
\hline NIP & 265 & 30.3 & 8.7 & - & 265 & 89 & 3.0 & - \\
\hline
\end{tabular}




$$
\begin{aligned}
\log \left(Q_{\mathrm{e}}-Q_{\mathrm{t}}\right) & =\log Q_{\mathrm{e}}-\frac{k_{1} t}{2.303} \\
\frac{t}{Q_{\mathrm{t}}} & =\frac{1}{k_{2} \mathrm{Q}_{\mathrm{e}}{ }^{2}}+\frac{1}{Q_{\mathrm{e}}} t
\end{aligned}
$$

where: $Q_{\mathrm{t}}$ is the adsorption capacity $\left(\mathrm{mg} \cdot \mathrm{g}^{-1}\right)$ at any time $t(\mathrm{~min})$; $\mathrm{Q}_{\mathrm{e}}$ is the adsorption capacity at equilibrium $\left(\mathrm{mg}^{-1}\right) ; k_{1}$ and $k_{2}$ are pseudo-first-order $\left(\mathrm{min}^{-1}\right)$ and pseudo-second-order


and Chimuka, 2016b). The correlation coefficients $\left(R^{2}\right)$ obtained for pseudo-first-order and pseudo-second-order models were 0.014 and 0.996 , respectively. These indicate that the data fitted well with the pseudo-second-order kinetic model, which translates to the chemisorption of ketoprofen onto MIP particles. This was likely to be through $\mathrm{H}$-bonding between the nitrogen atom of 2-vinylpyridine and the hydrogen atom in the carboxylic group of ketoprofen. The H-bonding of the template and the functional monomer was confirmed by computational modelling studies, as discussed earlier. Pseudo-second-order further meant that the target compound gets adsorbed onto two or more active binding sites on the surface of the MIP (Mata et al., 2014). The calculated adsorption capacity at equilibrium $\left(Q_{\mathrm{e}}\right)$ for MIP, based on the favourable pseudo-second-order model, was $3.22 \mathrm{mg}^{-1}{ }^{-1}$, whereas the experimental value was $0.12 \mathrm{mg} \cdot \mathrm{g}^{-1}$. The pseudo-second-order sorption rate constant $\left(k_{2}\right)$ obtained for MIP when employing the kinetics models was $0.25 \mathrm{mg} \cdot \mathrm{g}^{-1} \cdot \mathrm{min}^{-1}$.

Isothermal analysis of the polymers was done using Eqs 9 and 10 for the linearized forms of the Freundlich and Langmuir isotherms, respectively.

$$
\begin{aligned}
\log Q & =\frac{1}{n} \log C_{\mathrm{e}}+\log \alpha \\
\frac{C_{\mathrm{e}}}{Q} & =\frac{C_{\mathrm{e}}}{Q_{\max }}+\frac{1}{Q_{\max } K_{\mathrm{L}}}
\end{aligned}
$$

where: $Q$ is the amount of the adsorbed molecule at equilibrium $\left(\mathrm{mg} \cdot \mathrm{g}^{-1}\right), n$ is the Freundlich exponent depicting the adsorption intensity, $C_{\mathrm{e}}$ is the equilibrium concentration of the target molecule $\left(\mathrm{mg} \cdot \mathrm{L}^{-1}\right), \alpha$ is the adsorption capacity of the target molecule $\left(\mathrm{mg} \cdot \mathrm{g}^{-1}\right), Q_{\max }$ is the maximum adsorption capacity $\left(\mathrm{mg}^{-1}\right)$ and $K_{\mathrm{L}}$ is the Langmuir adsorption equilibrium constant (Madikizela and Chimuka, 2016b; Mata et al., 2014). Linear plots were obtained for both Langmuir and Freundlich isotherms (Fig. A3); however, the larger $R^{2}$ for MIP (Table 4) in the Langmuir model indicates that the monolayer adsorption of ketoprofen at homogeneous binding sites was dominant. In addition, the results depicted in Table 4 show the $Q_{\max }$ of 8.7 $\mathrm{mg} \cdot \mathrm{g}^{-1}$ for MIP obtained from the Langmuir isotherm, which is close to the experimental maximum adsorption capacity shown in Fig. 9. Furthermore, the calculated $n$ values (Table 4) are greater than 1 , which indicates a favourable adsorption process, but due to low a values indicating the adsorption capacity, the Freundlich model was not considered as the best isotherm. A similar observation has been reported in literature, where comparable $R^{2}$ values for both Langmuir and Freundlich isotherms were achieved but due to the closeness of the $Q_{\max }$ values to the experimental adsorption capacity, the Langmuir model was described as the best fit (Pakade et al., 2017).

\section{Environmental application}

Data presented in this work describe the nature of adsorption for ketoprofen onto MIP particles. In a recent study, it has been demonstrated that the MIP prepared in this study is capable of adsorbing ketoprofen from wastewater (Zunngu et al., 2017). In this study (Zunngu et al., 2017), MIP was packed in the solidphase extraction (SPE) cartridge and applied as sorbent in the determination of ketoprofen from wastewater using HPLC. Furthermore, the reported recovery obtained for wastewater spiked with ketoprofen was $68 \%$, whereas the method detection limits of 0.23 and $0.17 \mu \mathrm{g} \cdot \mathrm{L}^{-1}$ were achieved for wastewater influent and effluent, respectively. Upon application for environmental monitoring of ketoprofen in wastewater treatment plants, the drug was quantified in 3 wastewater influents and effluents at concentration ranges of 22.5-34.0 and $1.14-5.33 \mu \mathrm{g} \cdot \mathrm{L}^{-1}$, respectively. Despite the MIP's successful application as SPE sorbent in our previous work (Zunngu et al., 2017), there was no detailed information on the nature of binding and factors that could affect ketoprofen adsorption from contaminated water. Such information is important in order to ensure the complete removal of ketoprofen from contaminated water.

\section{CONCLUSION}

In this study, molecular dynamics simulation has indicated that ketoprofen interacts with 2-vinylpyridine through hydrogen bonding, which was further confirmed experimentally, where maximum adsorption of ketoprofen on MIP occurred under acidic conditions. Under acidic conditions, ketoprofen is protonated, which results in strong interactions with the nitrogen atom of 2-vinylpyridine in the MIP. Also, high extraction efficiency for ketoprofen molecules was observed, which is related to the high binding energy that was obtained for ketoprofen-2-vinylpridine complex in the molecular dynamics simulation. Furthermore, 2-vinylpyridine was computationally demonstrated as the suitable functional monomer in the synthesis of MIP for ketoprofen. The synthesized MIP was characterized by SEM, which showed that the surface of the MIP was rougher when compared to the NIP. Based on BET analysis, MIP had a larger surface area and total pore

\begin{tabular}{|l|c|c|c|c|c|c|}
\hline \multicolumn{7}{|c|}{ TABLE 4 } \\
\hline \multirow{2}{*}{ Polymer } & \multicolumn{7}{|c|}{ Data extracted from the adsorption isotherms } \\
\cline { 2 - 8 } & $R^{2}$ & $K_{L}\left(\mathrm{~L} \cdot \mathrm{mg}^{-1}\right)$ & $\mathrm{Q}_{\max }\left(\mathbf{m g}^{-1} \mathbf{g}^{-1}\right)$ & $R^{2}$ & $n$ & $\alpha$ \\
\hline MIP & 0.992 & 0.21 & 8.7 & 0.989 & 2.11 & 1.80 \\
\hline NIP & 0.991 & 0.15 & 9.4 & 0.992 & 2.05 & 1.82 \\
\hline
\end{tabular}


volume than the NIP, which resulted in higher sample load capacity. The NMR results showed no differences in the chemical shifts obtained for MIP and NIP, which indicates that both polymers were chemically equivalent. Similar FTIR spectra were as a result of both MIP and NIP having a similar backbone structure. Although similarities were observed for both MIP and NIP in NMR and FTIR data, selectivity experiments proved MIP to be more selective to ketoprofen, due to the imprinting effect, in the presence of fenoprofen and gemfibrozil. Selectivity was observed to be 8 and 2 times greater for ketoprofen in the present of fenoprofen and gemfibrozil, respectively, compared to the NIP. The extraction efficiencies achieved for the ketoprofen when using MIP were between 70 and $100 \%$. From the perspective of contact time, kinetics of sorption followed the pseudo-second-order model, further emphasizing the chemisorption mechanism. Using the initial concentration data, the Langmuir adsorption isotherms provided the best fitting model, which indicated that chemisorption of ketoprofen occurred on the homogeneous binding sites of the MIP.

\section{ACKNOWLEDGEMENTS}

Funding from National Research Foundation of South Africa (Grant numbers: TTK150618119659, TTK14042666625 and 114415) and Eskom through Tertiary Education Support Program are acknowledged. The Centre for High Performance Computing is thanked for access to computational facilities.

\section{REFERENCES}

AGUNBIADE FO and MOODLEY B (2016) Occurrence and distribution pattern of acidic pharmaceuticals in surface water, wastewater, and sediment of the Msunduzi River, KwaZulu-Natal, South Africa. Environ. Toxicol. Chem. 35 36-46. https://doi. org/10.1002/etc. 3144

AUGUSTO F, CARASEK E, SILVA RGC, RIVELLINO SR and DOMINGUES A (2010) New sorbents for extraction and microextraction techniques. J. Chromatogr. A 1217 2533-2542. https://doi.org/10.1016/j.chroma.2009.12.033

BAYEN S, ZHANG H, DESAI MM, OOI SK and KELLY BC (2013) Occurrence and distribution of pharmaceutically active and endocrine disrupting compounds in Singapore's marine environment: influence of hydrodynamics and physical-chemical properties. Environmental pollution. Environ. Pollut. 182 1-8. https://doi.org/10.1016/j.envpol.2013.06.028

CORMACK PAG and ELORZA AZ (2004) Molecularly imprinted polymers: synthesis and characterization. J. Chromatogr. B 804 173-182. https://doi.org/10.1016/j.jchromb.2004.02.013

DAI CM, ZHANG J, ZHANG YL, ZHOU XF, DUAN YP and LIU SG (2012) Selective removal of acidic pharmaceuticals from contaminated lake water using multi-templates molecularly imprinted polymer. Chem. Eng. J. 211-212 302-309. https://doi. org/10.1016/j.cej.2012.09.090

DONG C, LI X, GUO Z and QI J (2009) Development of a model for the rational design of molecular imprinted polymer: computational approach for combined molecular dynamics/quantum mechanics calculations. Anal. Chim. Acta 647 117-124. https://doi. org/10.1016/j.aca.2009.05.040

FARRINGTON K, MAGNER E and REGAN F (2006) Predicting the performance of molecularly imprinted polymers: Selective extraction of caffeine by molecularly imprinted solid phase extraction. Anal. Chim. Acta 566 60-68. https://doi.org/10.1016/j.aca.2006.02.057

FARRINGTON K and REGAN F (2007) Investigation of the nature of MIP recognition: The development and characterisation of a MIP for Ibuprofen. Biosens. Bioelectron. 22 1138-1146. https://doi. org/10.1016/j.bios.2006.06.025
FÉLIX-CAÑEDO TE, DURÁN-ÁLVAREZ JC and JIMÉNEZCISNEROS B (2013) The occurrence and distribution of a group of organic micropollutants in Mexico City's water sources. Sci. Total Environ. 454-455 109-118. https://doi.org/10.1016/j. scitotenv.2013.02.088

FENG Q, ZHAO L and LIN JM (2009) Molecularly imprinted polymer as micro-solid phase extraction combined with high performance liquid chromatography to determine phenolic compounds in environmental water samples. Anal. Chim. Acta 650 70-76. https:// doi.org/10.1016/j.aca.2009.04.016

FERRARI B, PAXEUS N, GIUDICE RL, POLLIO A and GARRIC J (2003) Ecotoxicological impact of pharmaceuticals found in treated wastewaters: study of carbamazepine, clofibric acid, and diclofenac. Ecotoxicol. Environ. Saf. 55 359-370. https://doi.org/10.1016/ S0147-6513(02)00082-9

GHOLIVAND MB, KARIMIAN N and MALEKZADEH G (2012) Computational design and synthesis of a high selective molecularly imprinted polymer for voltammetric sensing of propazine in food samples. Talanta 89 513-520. https://doi.org/10.1016/j. talanta.2012.01.001

HAN Y, GU L, ZHANG M, LI Z, YANG W, TANG X and XIE G (2017) Computer-aided design of molecularly imprinted polymers for recognition of atrazine. Comput. Theor. Chem. 1121 29-34. https:// doi.org/10.1016/j.comptc.2017.10.011

HANAMOTO S, HASEGAWA E, NAKADA N, YAMASHITA N and TANAKA H (2016) Modeling the fate of a photoproduct of ketoprofen in urban rivers receiving wastewater treatment plant effluent. Sci. Total Environ. 573 810-816. https://doi.org/10.1016/j. scitotenv.2016.08.189

KERMIA AEB, FOUIAL-DJEBBAR and TRARI M (2016) Occurrence, fate and removal efficiencies of pharmaceuticals in wastewater treatment plants (WWTPs) discharging in the coastal environment of Algiers. $C R$ Chim. 19 963-970. https://doi.org/10.1016/j.crci.2016.05.005

KIZHAKEKUTHIATHOTTIL MA and BEENA M (2011) Design of 2,4-dichlorophenoxyacetic acid imprinted polymer with high specificity and selectivity. Mater. Sci. Appl. 2 131-140.

KUBO T and OTSUKA K (2016) Recent progress for the selective pharmaceutical analyses using molecularly imprinted adsorbents and their related techniques: A review. J. Pharm. Biomed. Anal. 130 68-80. https://doi.org/10.1016/j.jpba.2016.05.044

KYZAS GZ, FU J, LAZARIDIS NK, BIKIARIS DN and MATIS KA (2015) New approaches on the removal of pharmaceuticals from wastewaters with adsorbent materials. J. Mol. Liq. 209 87-93. https://doi.org/10.1016/j.molliq.2015.05.025

LAVEN M, ALSBERG T, YU Y, ADOLFSSON-ERICI M and SUN H (2009) Serial mixed-mode cation- and anion-exchange solid-phase extraction for separation of basic, neutral and acidic pharmaceuticals in wastewater and analysis by highperformance liquid chromatography-quadrupole time-of-flight mass spectrometry. J. Chromatogr. A 1216 49-62. https://doi. org/10.1016/j.chroma.2008.11.014

MADIKIZELA LM and CHIMUKA L (2016a) Determination of ibuprofen, naproxen and diclofenac in aqueous samples using a multi-template molecularly imprinted polymer as selective adsorbent for solid-phase extraction. J. Pharm. Biomed. Anal. 128 210-215. https://doi.org/10.1016/j.jpba.2016.05.037

MADIKIZELA LM and CHIMUKA L (2016b) Synthesis, adsorption and selectivity studies of a polymer imprinted with naproxen, ibuprofen and diclofenac. J. Environ. Chem. Eng. 4 4029-4037. https://doi.org/10.1016/j.jece.2016.09.012

MADIKIZELA LM, MDLULI PS and CHIMUKA L (2016) Experimental and theoretical study of molecular interactions between 2-vinyl pyridine and acidic pharmaceuticals used as multi-template molecules in molecularly imprinted polymer. React. Funct. Polym. 103 33-43. https://doi.org/10.1016/j. reactfunctpolym.2016.03.017

MADIKIZELA LM, MUTHWA SF and CHIMUKA L (2014) Determination of triclosan and ketoprofen in river water and wastewater by solid-phase extraction and high performance liquid chromatography. S Afr. J. Chem. 67 143-150.

MADRAKIAN T, AHMADI M, AFKHAMI A and SOLEIMANI M (2013) Selective solid-phase extraction of naproxen drug from human urine samples using molecularly imprinted 
polymer-coated magnetic multi-walled carbon nanotubes prior to its spectrofluorometric determination. Analyst 138 4542-4549. https://doi.org/10.1039/c3an00686g

MARTINEZ-SENA T, ARMENTA S, DE LA GUARDIA M and ESTEVE-TURRILLAS FA (2016) Determination of nonsteroidal anti-inflammatory drugs in water and urine using selective molecular imprinted polymer extraction and liquid chromatography. J. Pharm. Biomed. Anal. 131 48-53. https://doi. org/10.1016/j.jpba.2016.08.006

MATA KD, CORAZZA MZ, DE OLIVEIRA FM, DE TOFFOLI AL, TARLEY CRT and MOREIRA AB (2014) Synthesis and characterization of cross-linked molecularly imprinted polyacrylamide for the extraction/preconcentration of glyphosate and aminomethylphosphonic acid from water samples. React. Funct. Polym. 83 76-83. https://doi.org/10.1016/j. reactfunctpolym.2014.07.004

MEISCHL F, SCHEMETH D, HARDER M, KÖPFLE N, TESSADRI R and RAINER M (2016) Synthesis and evaluation of a novel molecularly imprinted polymer for the selective isolation of acetylsalicylic acid from aqueous solutions. J. Environ. Chem. Eng. 4 4083-4090. https://doi.org/10.1016/j.jece.2016.09.013

MONTI S, CAPPELLI C, BRONCO S, GIUSTI P and CIARDELLI G (2006) Towards the design of highly selective recognition sites into molecular imprinting polymers: a computational approach. Biosens. Bioelectron. 22 153-163. https://doi.org/10.1016/j. bios.2006.05.017

MURRAY A and ÖRMECI B (2012) Application of molecularly imprinted and non-imprinted polymers for removal of emerging contaminants in water and wastewater treatment: a review. Environ. Sci. Pollut. Res. 19 3820-3830. https://doi.org/10.1007/ s11356-012-1119-2

NAGHDI M, TAHERAN M, BRAR SK, KERMANSHAHI-POUR A, VERMA M and SURAMPALLI RY (2018) Removal of pharmaceutical compounds in water and wastewater using fungal oxidoreductase enzymes. Environ. Pollut. 234 190-213. https://doi. org/10.1016/j.envpol.2017.11.060

NAVARRO-VILLOSLADA F, VICENTE BS and MORENO-BONDI MC (2004) Application of multivariate analysis to the screening of molecularly imprinted polymers for bisphenol A. Anal. Chim. Acta 504 149-162. https://doi.org/10.1016/S0003-2670(03)00766-9

O'MAHONY J, KARLSSON BCG and MIZAIKOFF B (2007) Correlated theoretical, spectroscopic and X-ray crystallographic studies of a non-covalent molecularly imprinted polymerisation system. Analyst 132 1161-1168. https://doi.org/10.1039/b706258c

PAKADE V, CUKROWSKA E, DARKWA J, TORTO N and CHIMUKA L (2011) Selective removal of chromium (VI) from sulphates and other metal anions using an ion-imprinted polymer. Water SA 37 529-538. https://doi.org/10.4314/wsa.v37i4.11

PAKADE VE, MOLEFE ED and TAVENGWA NT (2017) Quantitative determination of trace concentrations of quercetin from prickly skin complex sample extracts by application of molecularly imprinted polymers. J. Environ. Chem. Eng. 5 1186-1195. https:// doi.org/10.1016/j.jece.2017.01.051

PATROLECCO L, ADEMOLLO N, GRENNI P and TOLOMEI A (2013) Simultaneous determination of human pharmaceuticals in water samples by solid phase extraction and HPLC with UV-fluorescence detection. Microchem. J. 107 165-171. https://doi. org/10.1016/j.microc.2012.05.035

PAVLOVIĆ DM, BABIC S, HORVAT AJM and KASTELAN-MACAN M (2007) Sample preparation in analysis of pharmaceuticals. TrAC, Trends Anal. Chem. 26 1062-1075. https://doi.org/10.1016/j. trac.2007.09.010

PENA T, CASAIS C, MEJUTO C and CELA R (2008) Development of a matrix solid-phase dispersion method for the determination of polycyclic aromatic hydrocarbons in sewage sludge samples. Anal. Chim. Acta 626 155-165. https://doi.org/10.1016/j.aca.2008.07.053

PUZIO K, DELEPEE R, VIDAL R and AGROFOGLIO LA (2013) Combination of computational methods, adsorption isotherms and selectivity tests for the conception of a mixed non-covalent-semicovalent molecularly imprinted polymer of vanillin. Anal. Chim. Acta 790 47-55. https://doi.org/10.1016/j.aca.2013.06.036

RIAHI S, EDRIS-TABRIZI F, JAVANBAKHT M, GANJALI MR and P. NOROUZI (2009) A computational approach to studying monomer selectivity towards the template in an imprinted polymer. J. Mol. Model. 15 829-836. https://doi.org/10.1007/s00894-008-0437-2

ROSTAMIZADEH K, VAHEDPOUR M and BOZORGI S (2012) Synthesis, characterization and evaluation of computationally designed nanoparticles of molecular imprinted polymers as drug delivery systems. Int. J. Pharm. 424 67-75. https://doi.org/10.1016/j. ijpharm.2011.12.054

SANTOS JL, APARICIO I, ALONSO E and CALLEJON M (2005) Simultaneous determination of pharmaceutically active compounds in wastewater samples by solid phase extraction and high-performance liquid chromatography with diode array and fluorescence detectors. Anal. Chim. Acta 550 116-122. https://doi. org/10.1016/j.aca.2005.06.064

SKOGSBERG U, MEYER C, REHBEIN J, FISCHER G, SCHAUFF S, WELSH N, ALBERT K, HALL AJ and SELLERGREN B (2007) A solid-state and suspended-state magic angle spinning nuclear magnetic resonance spectroscopic investigation of a 9-ethyladenine molecularly imprinted polymer. Polymer 48 229-238. https://doi. org/10.1016/j.polymer.2006.10.036

SOBIECH M, ZOLEK T, LULINSKI P and MACIEJEWSKA D (2014) A computational exploration of imprinted polymer affinity based on voriconazole metabolites. Analyst 139 1779-1788. https://doi. org/10.1039/c3an01721d

SOBIECH M, ZOLEK T, LULINSKI P and MACIEJEWSKA $\mathrm{D}$ (2016) Separation of octopamine racemate on $(R, S)-2$ amino-1-phenylethanol imprinted polymer - Experimental and computational studies. Talanta 146 556-567. https://doi. org/10.1016/j.talanta.2015.05.074

SONG R, HU X, GUAN P, LI J, QIAN L, WANG C and WANG Q (2015) Synthesis of porous molecularly imprinted polymers for selective adsorption of glutathione. Appl. Surf. Sci. 332 159-166. https://doi.org/10.1016/j.apsusc.2015.01.165

SPONGBERG AL, WITTER JD, ACUNA J, VARGAS J, MURILLO M, UMANA G, GOMEZ E and PEREZ G (2011) Reconnaissance of selected PPCP compounds in Costa Rican surface waters. Water Res. 45 6709-6717. https://doi.org/10.1016/j.watres.2011.10.004

STUMM-ZOLLINGER E and FAIR GM (1965) Biodegradation of steroid hormones. J. Water Pollut. Control Fed. 37 1506-1510.

SUN Z, SCHUSSLER W, SENGL M, NIESSNER R and KNOPP D (2008) Selective trace analysis of diclofenac in surface and wastewater samples using solid-phase extraction with a new molecularly imprinted polymer. Anal. Chim. Acta 620 73-81. https://doi.org/10.1016/j.aca.2008.05.020

SURIYANARAYANAN S, MANDAL S, RAMANUJAM K and NICHOLLS IA (2017) Electrochemically synthesized molecularly imprinted polythiophene nanostructures as recognition elements for an aspirin-chemosensor. Sens. Actuator B-Chem. 253 428-436. https://doi.org/10.1016/j.snb.2017.05.076

TAVENGWA NT, CUKROWSKA E and CHIMUKA L (2014) Preparation, characterization and application of $\mathrm{NaHCO}_{3}$ leached bulk U(VI) imprinted polymers endowed with $\gamma$-MPS coated magnetite in contaminated water. J. Hazard. Mater. 267 221-228. https://doi.org/10.1016/j.jhazmat.2013.12.053

TAVENGWA NT, CUKROWSKA E and CHIMUKA L (2013) Synthesis, adsorption and selectivity studies of N-propyl quaternized magnetic poly(4-vinylpyridine) for hexavalent chromium. Talanta 116 670-677. https://doi.org/10.1016/j. talanta.2013.07.034

TIWARI B, SELLAMUTHU B, OUARDA Y, DROGUI P, TYAGI RD and BUELNA G (2017) Review on fate and mechanism of removal of pharmaceutical pollutants from wastewater using biological approach. Bioresour. Technol. 224 1-12. https://doi.org/10.1016/j. biortech.2016.11.042

TOGOLA A and BUDZINSKI H (2007) Analytical development for analysis of pharmaceuticals in water samples by SPE and GCMS. Anal. Bioanal. Chem. 388 627-635. https://doi.org/10.1007/ s00216-007-1251-x

WANG JY, LIANG Z, WU P and YIN SJ (2009) Binding constant and transport property of S-Naproxen molecularly imprinted composite membrane. J. Membr. Sci. 331 84-90. https://doi. org/10.1016/j.memsci.2009.01.016

XU L, PAN J, DAI J, LI X, HANG H, CAO Z and YAN Y (2012) Preparation of thermal-responsive magnetic molecularly imprinted 
polymers for selective removal of antibiotics from aqueous solution. J. Hazard. Mater. 233-234 48-56. https://doi.org/10.1016/j. jhazmat.2012.06.056

YU Y, WU L and CHANG AC (2013) Seasonal variation of endocrine disrupting compounds, pharmaceuticals and personal care products in wastewater treatment plants. Sci. Total Environ. 442 310-316. https://doi.org/10.1016/j.scitotenv.2012.10.001

ZHANG H, SONG T, ZONG F, CHEN T and FAN C (2008) Synthesis and characterization of molecularly imprinted polymers for phenoxyacetic Acids. Int. J. Mol. Sci. 9 98-106. https://doi.org/10.3390/ijms9010098
ZORITA S, BOYD B, JONSSON S, SVENSSON EYC, MATHIASSON $\mathrm{L}$ and BERGSTROM S (2008) Selective determination of acidic pharmaceuticals in wastewater using molecularly imprinted solid-phase extraction. Anal. Chim. Acta 626 147-154. https://doi. org/10.1016/j.aca.2008.07.051

ZUNNGU SS, MADIKIZELA LM, CHIMUKA L and MDLULI PS

(2017) Synthesis and application of a molecularly imprinted polymer in the solid-phase extraction of ketoprofen from wastewater. $C R$ Chim. 20 585-591. https://doi.org/10.1016/j.crci.2016.09.006 
TABLE A1

Chemical structures and physicochemical properties of ketoprofen and compounds used as competitors (Naghdi et al., 2018)

\begin{tabular}{|c|c|c|c|c|c|}
\hline Chemical compound & Chemical structure & MW & $p K a$ & $\log K_{\mathrm{ow}}$ & Water solubility $\left(\mathrm{mg} \cdot \mathrm{L}^{-1}\right)$ \\
\hline Ketoprofen & & 254 & 4.29 & 3.12 & 51 \\
\hline Fenoprofen & & 242 & 4.21 & 3.90 & Slight \\
\hline Gemfibrozil & & 250 & 4.45 & 4.77 & 11 \\
\hline
\end{tabular}

MW: molecular weight $\left(\mathrm{g} \cdot \mathrm{mol}^{-1}\right)$
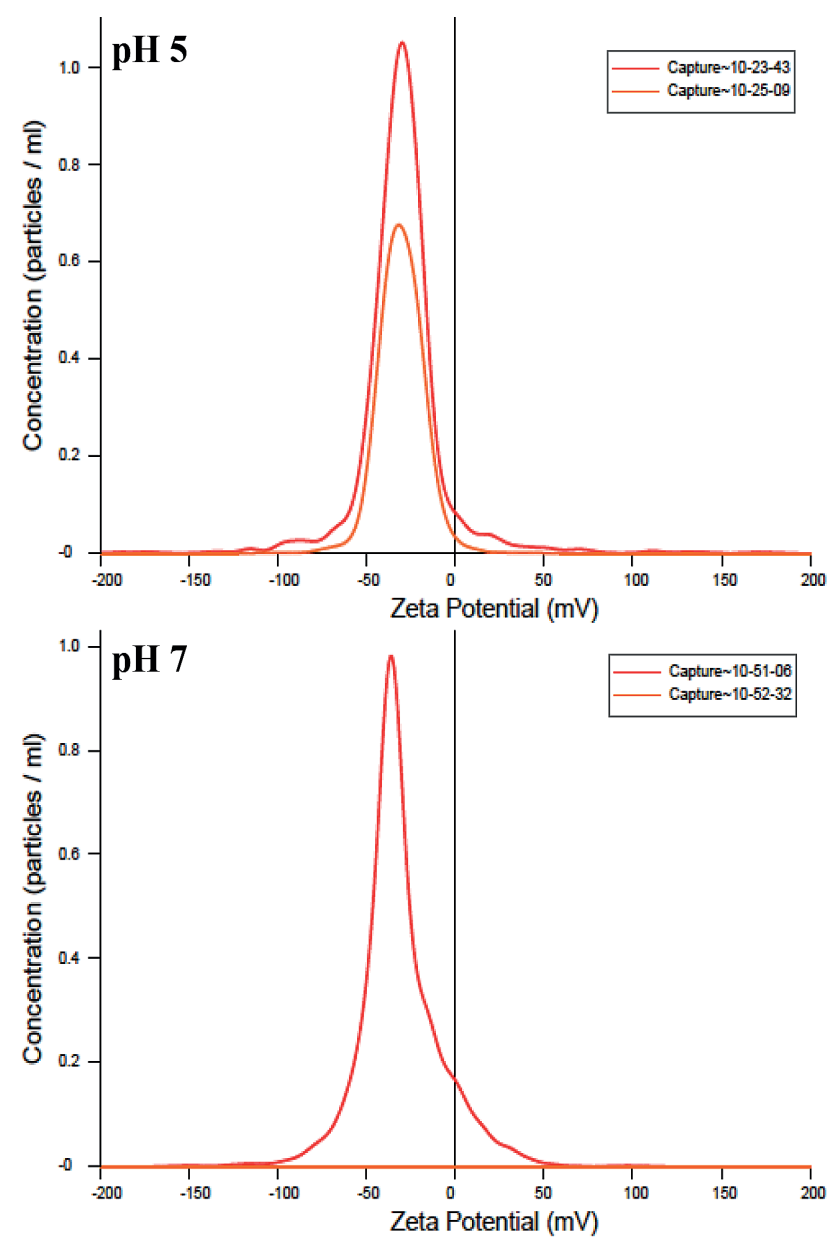

Figure A1

Zeta potential curves for MIP dispersed in water at $\mathrm{pH} 5$ and $\mathrm{pH} 9$ 

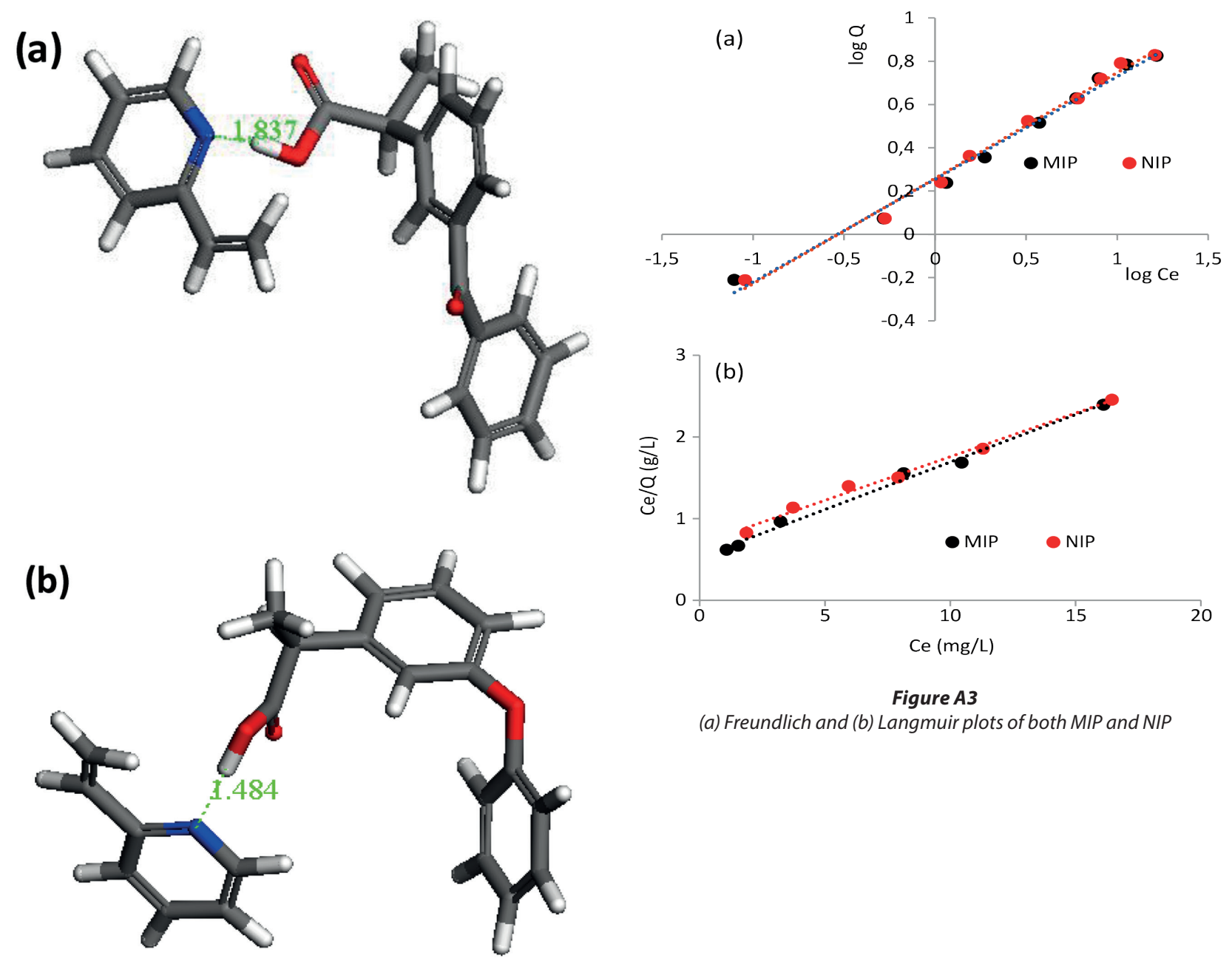

Figure A3

(a) Freundlich and (b) Langmuir plots of both MIP and NIP

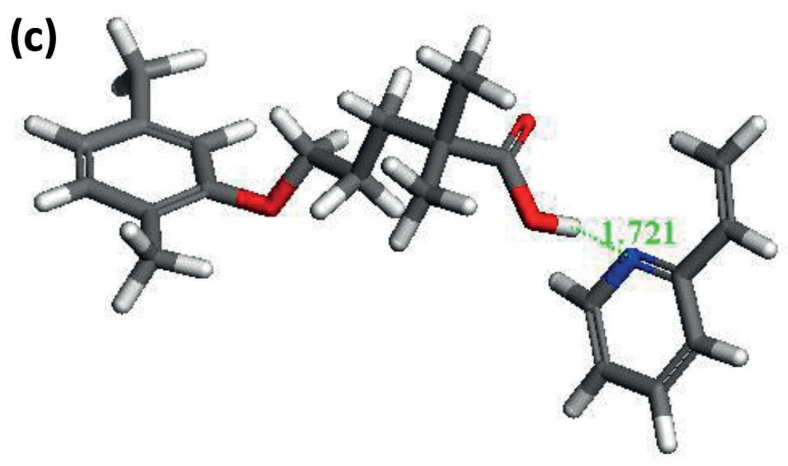

\begin{tabular}{|c|c|c|}
\hline & $\begin{array}{l}\text { Bond distance } \\
\text { (Å) }\end{array}$ & $\begin{array}{l}\Delta \mathrm{E} \\
\left(\text { Kcal.mol }^{-1}\right)\end{array}$ \\
\hline Ketoprofen & 1.837 & -11.97 \\
\hline Gemfibrozil & 1.721 & -16.32 \\
\hline Fenoprofen & 1.484 & -18.20 \\
\hline
\end{tabular}

Figure A2

Complex formation between ketoprofen and 2-vinylpyridine (a), fenoprofen and 2-vinylpyridine (b), and gemfibrozil and 2-vinylpyridine (c) 